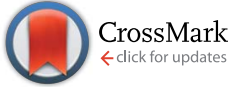

Cite this: Chem. Sci., 2016, 7, 219

\title{
Boron-doped nanographene: Lewis acidity, redox properties, and battery electrode performance $\uparrow$
}

\author{
Shinichiro Osumi, ${ }^{a}$ Shohei Saito, ${ }^{* a}$ Chuandong Dou, ${ }^{a}$ Kyohei Matsuo, ${ }^{a}$ Keita Kume, ${ }^{a}$ \\ Hirofumi Yoshikawa, $\ddagger^{a}$ Kunio Awaga ${ }^{a}$ and Shigehiro Yamaguchi ${ }^{\star a b c}$
}

\begin{abstract}
The preparation of boron-doped nanocarbon scaffolds with well-defined structures is important for the understanding of the impact of boron doping on their properties and behavior at the molecular level. We recently succeeded in the synthesis of a structurally well-defined nanographene molecule, bearing two boron atoms at the central positions. In this study, the characteristic properties and functions of this boron-doped nanographene were investigated in terms of (1) Lewis acidity, (2) redox properties, and (3) electrode performance in a battery. This boron-doped nanographene was susceptible to chemical adsorption with various Lewis bases, resulting in significant changes in the absorption and fluorescence properties, as well as in the conformation of the honeycomb framework. The two-electron reduction of this boron-doped nanographene produced a dianionic species that showed a substantial biradical character with a triplet ground state. A Li battery electrode, composed of a boron-doped nanographene with small peripheral substituents, displayed a stable performance in the 1.5-4.0 $\mathrm{V}$ range with a first discharge capacity of $160 \mathrm{~mA} \mathrm{~h} \mathrm{~g}^{-1}$. These results provide important insights into the effect of boron doping on nanocarbon compounds.
\end{abstract}

Received 22nd June 2015

Accepted 24th September 2015

DOI: $10.1039 /$ c5sc02246k

www.rsc.org/chemicalscience

reported by two independent groups. ${ }^{6}$ Conventional preparation methods, such as chemical vapor deposition, ${ }^{7}$ reductive coupling in solution, ${ }^{8}$ or thermal annealing, ${ }^{9}$ inevitably produce a mixture of boron-doped graphene compounds, which differ in size, edge structure, and doping pattern. In order to understand the impact of boron doping at the molecular level, the preparation of structurally well-defined boron-doped graphene is indispensible.

In order to obtain graphene systems with a uniform structure, a bottom-up synthesis from a defined organic precursor represents a promising approach. ${ }^{10}$ This technique is also effective for the synthesis of the doped graphene systems. ${ }^{6,11}$ So far, nitrogen-doped nanographene scaffolds with precise atomic structures have been successfully synthesized. ${ }^{12}$ The synthesis of boron-doped nanographene, on the other hand, still remains challenging due to the intrinsic instability of tricoordinate organoboranes towards oxygen and moisture. One strategy to circumvent this obstacle is the incorporation of nitrogen atoms in the form of $\mathrm{B}-\mathrm{N}$ units. ${ }^{13}$ Even though the chemical stability of the organoboranes is thus enhanced through the interaction between the lone pair of electrons on the nitrogen atom and the vacant $\mathrm{p}$ orbital of the boron atom, the intrinsic Lewis acidity of the boron atom is lost simultaneously.

Recently, we introduced the concept of "structural constraint" as an alternative stabilization strategy for organoboranes. ${ }^{14}$ This design paradigm is based on the enforced planarization of triphenylboranes via methylene tethers, and 


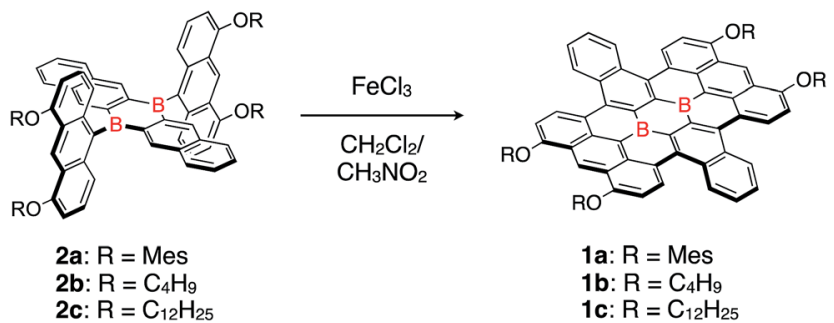

Scheme 1 Synthesis of a honeycomb lattice framework, bearing two boron atoms at the central positions.

resulted in great stability under ambient conditions. ${ }^{14 a}$ Using this strategy, a fully $\pi$-conjugated planar triarylborane, in which three aryl groups are directly fused with one another, was successfully produced. ${ }^{14 c}$ This success has also opened a new avenue for the precise synthesis of boron-doped nanographene scaffolds and enabled us to prepare a nanometer-sized honeycomb structure with two boron atoms at the central positions (Scheme 1). ${ }^{14 d}$

Experimental and theoretical studies on boron-doped nanographene 1a were able to reveal some of its characteristic properties arising from the presence of the two boron atoms, e.g. broad absorption bands in the visible region and reversible multi-redox processes. However, these findings describe merely parts of the chemistry of boron-doped nanographene. In this article, we disclose the following aspects of boron-doped nanographene: (1) Lewis acidity, (2) redox properties, and (3) electrode performance in batteries. These properties and functions are closely associated with the presence of the boron atoms and can thus be regarded as the impact of boron doping on pristine nanographene.

\section{Results and discussion}

\section{Synthesis and structure}

In the previously reported synthesis of boron-doped nanographene 1a, bulky mesityloxy groups were introduced at the peripheral positions of the $\pi$-conjugated skeleton. This structural feature enabled the suppression of strong aggregation and gave rise to sufficient solubility in common organic solvents (Table 1). However, the less densely packed structure, arising from the presence of these bulky substituents, is unfavorable for attaining high levels of molecule-based device performance in e.g. organic field-effect transistors (OFET) and battery electrodes. Small orbital overlap causes low carrier mobility in OFET applications ${ }^{15}$ and weak intermolecular interaction brings about dissolution of the battery electrode materials into electrolyte, resulting in low cycle performance. ${ }^{16}$ This potential

Table 1 Solubility of boron-doped nanographenes at $25^{\circ} \mathrm{C}$

\begin{tabular}{llll}
\hline Solvent & 1a & 1b & 1c \\
\hline Chlorobenzene & $4.8 \mathrm{mg} \mathrm{mL}^{-1}$ & $<1 \mathrm{mg} \mathrm{mL}^{-1}$ & $3.7 \mathrm{mg} \mathrm{mL}^{-1}$ \\
$o$-Dichlorobenzene & $10.8 \mathrm{mg} \mathrm{mL}^{-1}$ & $<1 \mathrm{mg} \mathrm{mL}^{-1}$ & $5.5 \mathrm{mg} \mathrm{mL}^{-1}$
\end{tabular}

drawback can be overcome by the use of sterically less demanding substituents. In order to investigate such substituent effects on the packing structure and material properties, alkoxy-substituted derivatives $\mathbf{1 b}$ and $\mathbf{1 c}$ were synthesized and examined in this study.

Butoxy- and dodecyloxy-substituted boron-doped nanographenes $\mathbf{1 b}$ and $\mathbf{1 c}$ were prepared as described for $\mathbf{1 a}$ (Scheme 1). The oxidative cyclodehydrogenation of dianthryl-substituted dihydrodiborapentacene precursors $2 \mathbf{b}$ and $2 \mathbf{c}$ using $\mathrm{FeCl}_{3}$ in a binary $\mathrm{CH}_{2} \mathrm{Cl}_{2} /$ nitromethane solvent afforded $\mathbf{1 b}$ and $\mathbf{1 c}$ in $19 \%$ and $34 \%$ yield, respectively. Their yields were slightly lower than that of $1 \mathrm{a}(51 \%),{ }^{14 d}$ most likely due to their low solubility in common organic solvents, which required a laborious purification procedure. The introduction of the electron-donating aryloxy or alkoxy groups at the 4,5-positions of the terminal anthracene moiety is crucial for promoting the cyclization. ${ }^{17}$ Compounds 1a-1c thus prepared are highly stable in air. Only subtle degradation was observed for $\mathbf{1 a}$ and $\mathbf{1 c}$ in toluene solutions in air even after 7 days by monitoring with the UVvisible absorption spectroscopy (Fig. S2†).

Single crystals of $\mathbf{1 b}$ and $\mathbf{1 c}$ were obtained from 1,2-dichloroethane/2-propanol and chlorobenzene/octane solutions, respectively. X-ray crystallographic analyses confirmed that both compounds contain the four alkoxy groups at the zig-zag edges of the nanographene skeleton (Fig. 1 for $\mathbf{1 b}$ and Fig. S20 $\dagger$ for 1c). The local $\mathrm{BC}_{3}$ sites adopt a planar geometry, in which the $\mathrm{B}-\mathrm{C}$ bonds $(1.50-1.54 \AA)$ are much shorter than those of non-fused triphenylboranes (1.57-1.59 $\mathrm{A})$. The nanographene skeletons in both $\mathbf{1 b}$ and $\mathbf{1 c}$ are deviated from planarity due to the steric repulsion between the hydrogen atoms in the cove regions, and accordingly $\mathbf{1 b}$ and $\mathbf{1 c}$ do not form $\pi$-stacked structures. However, due to their sterically less demanding substituents, $\mathbf{1 b}$ and $\mathbf{1 c}$ are more densely packed than $\mathbf{1 a}$. This is

(a)

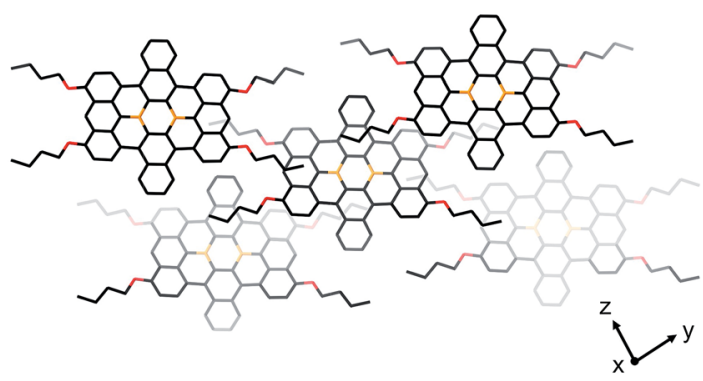

(b)

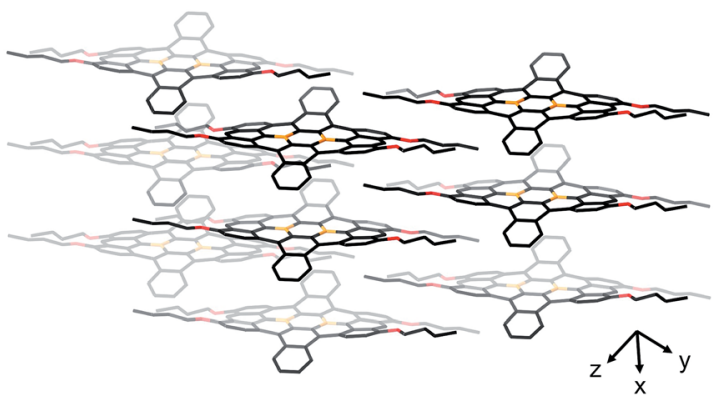

Fig. 1 Crystal packing of $1 \mathrm{~b}$ from (a) a top view and (b) a side view. Hydrogen atoms are omitted for clarity. Orange: boron; red: oxygen. 
consistent with the fact that $\mathbf{1 b}$ and $\mathbf{1 c}$ exhibit a significantly lower solubility than 1a (Table 1). The use of 9,10-dihydro-9,10diboraanthracene as a key precursor instead of 2 may potentially represent an option to generate an ideally planar fused skeleton and induce $\pi$-stacking. However, our previous study revealed that the treatment of this dihydrodiboraanthracene precursor with $\mathrm{FeCl}_{3}$ resulted in undesirable chlorination at the 1,8-position of the terminal anthracene moieties rather than cyclization. ${ }^{18}$ It should furthermore be noted that, in contrast to 1a, no solvent molecule was contained in the crystal packing of 1b and 1c.

The photophysical properties of $\mathbf{1 c}$ were investigated in $\mathrm{CH}_{2} \mathrm{Cl}_{2}$ (Fig. S1 $\dagger$ ). The absorption spectrum displayed a broad absorption band, which covered the entire visible region (400$700 \mathrm{~nm}$ ) and contained a maximum at $563 \mathrm{~nm}$. The fluorescence spectrum showed a broad emission band in the visibleNIR region with a maximum at $694 \mathrm{~nm}$. These results are comparable to those of 1a, and DFT calculations (B3LYP/6$31 \mathrm{G}^{*}$ ) supported the notion that the electronic structure of the nanographene scaffold remained unchanged upon substitution of the peripheral aryloxy groups with alkoxy groups (Fig. S22 $\dagger$ ).

\section{Lewis acidity}

We previously demonstrated that planarized triarylboranes maintain Lewis acidity and are able to form coordination complexes with Lewis bases despite their polycyclic structure. Specifically, we revealed dynamic $\mathrm{B}-\mathrm{N}$ bond formation processes in the presence of pyridine, which are responsible for the intriguing thermochromism ${ }^{\mathbf{1 4 c}}$ and photodissociation ${ }^{\mathbf{1 4 e}}$ observed for these B-N Lewis adducts. In this context, borondoped nanographene 1 is expected to form 1 : 2 Lewis acid-base adducts (Scheme 2), and either cis- or trans-coordination modes are possible. Even more importantly, the formation of such Lewis adducts can be regarded as a model for chemical adsorption processes on boron-doped graphene. The potential of boron-doped graphene for chemisorption has recently generated increasing attention, as this aspect may be beneficial for various applications, including chemical sensing, hydrogen storage, and surface-enhanced Raman scattering. ${ }^{19}$ Although several theoretical studies have addressed this issue, experimental insight still remains to be gathered. ${ }^{6 a}$ Therefore, we now evaluated the Lewis acidity of $\mathbf{1}$ in order to gain a quantitative understanding of the chemisorption properties of the local $\mathrm{BC}_{3}$ sites in the boron-doped nanographene.

Initially, boron-doped nanographene 1a was titrated with fluoride ions, i.e. with a strong Lewis base. Upon addition of

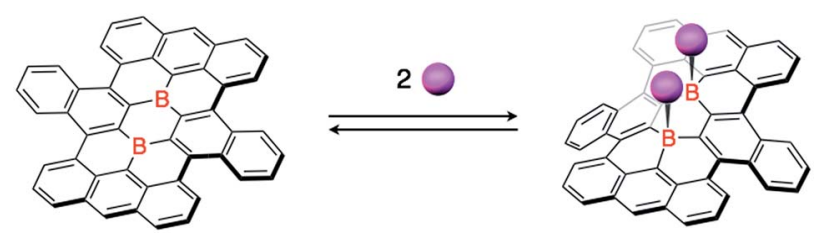

Scheme 2 Chemical adsorption of Lewis bases on a boron-doped honeycomb lattice structure. tetra- $n$-butylammonium fluoride (TBAF) to a THF solution of 1a, the color of the solution changed from purple to yellow. The corresponding UV-visible absorption spectra showed that the absorption bands of 1a around $390 \mathrm{~nm}$ and $580 \mathrm{~nm}$ disappeared, and that a new band appeared around $470 \mathrm{~nm}$ with increasing concentrations of fluoride ions (Fig. 2a). The spectral change continued until the addition of two equivalents of TBAF. The formation of $1: 2$ complexes was confirmed by a Job plot analysis. When $[\mathbf{1 a}]_{0}+[\mathrm{TBAF}]_{0}$ is kept constant, the absorbance of the Lewis adducts at $474 \mathrm{~nm}$ produces a maximum at a ratio of $\chi=0.37$, indicative of a $1: 2$ coordination mode (Fig. $2 b$ ). Even with weaker Lewis bases, such as pyridine, 4-methylpyridine (MePy), or 4-dimethylaminopyridine (DMAP), similar spectral changes were observed after the addition of an excess of these bases (Fig. S5-S7†). The ${ }^{11} \mathrm{~B}$ NMR spectrum of $\mathbf{1 b}$ in pyridine- $d_{5}$ showed a broad signal at $-2.78 \mathrm{ppm}$, supporting the generation of a tetracoordinate boron compound. ${ }^{20}$

Based on the titration of $1 \mathbf{a}$ with pyridine monitored by the UV-visible absorption spectroscopy and the spectral analysis using the nonlinear least-square fitting procedure, ${ }^{21}$ binding constants of $K_{1}=23 \mathrm{M}^{-1}$ and $K_{2}=16 \mathrm{M}^{-1}$ were determined for the first and second coordination steps at the two $\mathrm{BC}_{3}$ sites (Fig. S10 $\dagger$ ). Moreover, binding constants with MePy and DMAP were also determined to be $K_{1}=150 \mathrm{M}^{-1}, K_{2}=72 \mathrm{M}^{-1}$ and $K_{1}=$ $3.8 \times 10^{4} \mathrm{M}^{-1}, K_{2}=2.3 \times 10^{4} \mathrm{M}^{-1}$, respectively (Fig. S11 and $\mathrm{S} 12 \dagger)$. These results demonstrate that there is no significant allosteric effect for these systems. Notably, although the absorption spectra seemingly changed with isosbestic points during the titration, the careful inspection of the enlarged spectra showed the absence of clear isosbestic point (Fig. S3 and $\mathrm{S} 8 \dagger$ ), indicative of sequent formation of the mono and bis Lewis adducts. In the titration of 1a with DMAP, the nonlinear least-
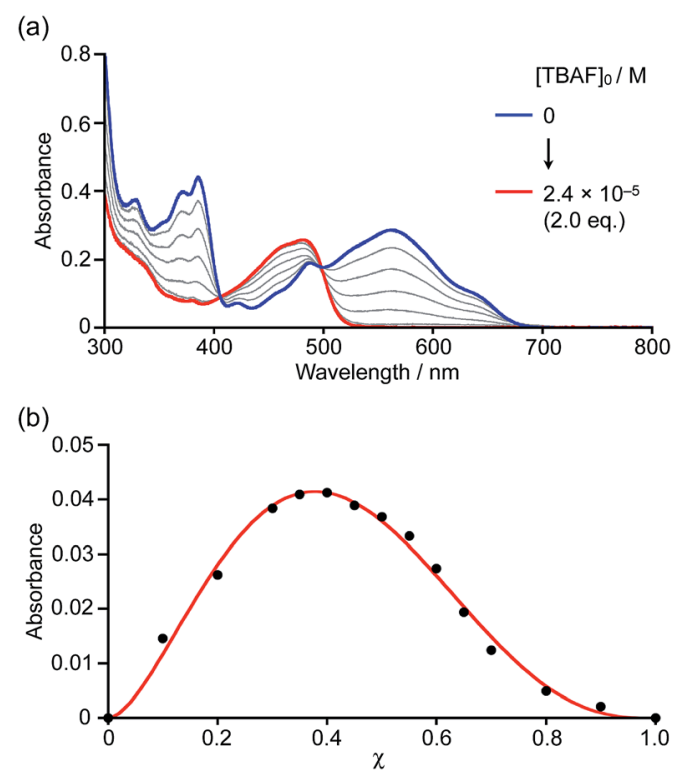

Fig. 2 (a) Spectral absorption change upon addition of TBAF to a THF solution of $1 \mathrm{a}\left(1.2 \times 10^{-5} \mathrm{M}\right)$ and (b) Job plot of $1 \mathrm{a}$ with TBAF, where the parameter $\chi$ is defined by $\chi=[1 \mathrm{a}]_{0} /\left([1 \mathrm{a}]_{0}+[\mathrm{TBAF}]_{0}\right)$. In this experiment: $[1 \mathrm{a}]_{0}+[\mathrm{TBAF}]_{0}=1.2 \times 10^{-5} \mathrm{M}$. 


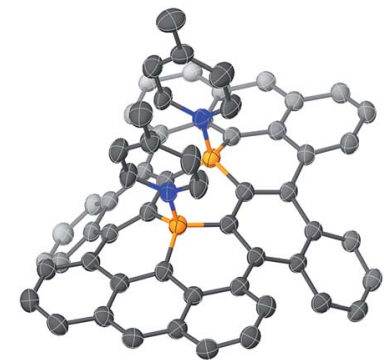

Fig. 3 Molecular structure of $1 \mathrm{~b} \cdot(\mathrm{MePy})_{2}$ (thermal ellipsoids set at $50 \%$ probability; butoxy substituents and hydrogen atoms are omitted for clarity). Orange: boron; blue: nitrogen.

square fitting of the absorption spectra allowed us to estimate the absorption spectrum of the mono Lewis adduct 1a-DMAP (Fig. S13†), in which the onset of the absorption band reaches longer wavelength compared to those of $1 \mathbf{a}$ and the bis Lewis adduct 1a-(DMAP) $)_{2}$. DFT structural optimization and TD-DFT calculations supported the smaller energy $S_{0} \rightarrow S_{1}$ transition of the mono Lewis adduct due to its donor-acceptor type electronic structure (Fig. $\mathrm{S} 24 \dagger$ ).

The structure of B-N Lewis adduct $\mathbf{1 b} \cdot(\mathbf{M e P y})_{2}$ was determined by single crystal X-ray diffraction analysis (Fig. 3). Single crystals of $\mathbf{1 b} \cdot(\mathbf{M e P y})_{2}$ were obtained from the slow diffusion of heptane into a solution of $\mathbf{1 b}$ in MePy. Notably, two molecules of MePy coordinate to the boron atoms in a cis fashion, i.e. on the same side of the honeycomb sheet. The two pyridine rings are closely aligned exhibiting an $\mathrm{N} \cdots \mathrm{N}$ distance of $3.23 \AA$, while the diborapentacene moiety was highly contorted. A dihedral angle of $89^{\circ}$ between the terminal benzene rings in the diborapentacene substructure and the B-N bond lengths of 1.665(2) $\AA$ and 1.664(2) $\AA$ were observed. Upon coordination, slightly elongated B-C bonds (0.063-0.090 A) relative to those in 1b were observed. The angle sums around both boron centers are $333^{\circ}$, which corresponds to a tetrahedral character of $86 \%{ }^{22}$ DFT calculations (B3LYP/6-311+G**) suggested that the cis-complex should be formed selectively in solution, as the cis-isomer is by $6.1 \mathrm{kcal} \mathrm{mol}^{-1}$ energetically more favorable than the transisomer (Fig. S23†).

Inspired by recent theoretical studies that proposed borondoped graphene as a promising material for gas sensors, ${ }^{19 a, e_{e} f}$ we exposed a solution of $\mathbf{1 a}$ to gaseous $\mathrm{NH}_{3}$. When $\mathrm{NH}_{3}$ was bubbled for a few seconds through a THF solution of 1a, the solution color changed from purple to yellow and a corresponding change of the absorption spectrum was observed (Fig. S9†). We also witnessed a drastic change of the fluorescence properties as a result of this process (Fig. 4 and movie in the $\mathrm{ESI}^{\dagger}$ ). In the absence of gaseous $\mathrm{NH}_{3}$, the THF solution of $\mathbf{1 a}$ showed only weak fluorescence in the visible-NIR region $\left(\Phi_{\mathrm{F}}=\right.$ 0.03), but after exposure to $\mathrm{NH}_{3}$, bright yellowish green fluorescence was observed at $526 \mathrm{~nm}\left(\Phi_{\mathrm{F}}=0.42\right)$.

Remarkable turn-on fluorescence was also observed in the titration experiments with strong bases, such as TBAF and DMAP. The significant fluorescence response was completed with the low concentration of $[\mathrm{TBAF}]=2.4 \times 10^{-5} \mathrm{M}$ or [DMAP]



(b)



Fig. 4 (a) Spectral change of the fluorescence upon bubbling $\mathrm{NH}_{3}$ through a THF solution of $1 \mathrm{a}\left(\lambda_{\mathrm{ex}}=440 \mathrm{~nm}\right)$ and (b) corresponding turn-on fluorescence response.

$=2.3 \times 10^{-3} \mathrm{M}$ when using a THF solution of $1 \mathrm{a}\left(1.2 \times 10^{-5} \mathrm{M}\right)$ (Fig. S4 and S7†). On the other hand, only weak fluorescence emerged even upon the addition of the high concentration of [pyridine] $=4.1 \times 10^{-1} \mathrm{M}$ or $[\mathrm{MePy}]=3.4 \times 10^{-1}$ (Fig. S5 and $\mathrm{S} 6 \dagger)$. Since the onset of the absorption band for the mono Lewis adduct reaches $700 \mathrm{~nm}$ (Fig. S13†), the increased yellowish green fluorescence around $530 \mathrm{~nm}$ should be attributed to the emission from the bis Lewis adduct, rather than the mono Lewis adduct, which may be non-emissive. Consequently, only the strong Lewis bases with high binding constants can give rise to the conspicuous fluorescence response. This finding would be important for the development of nanographene-based sensors.

\section{Redox properties}

The electrochemical properties of boron-doped nanographene 1a were previously examined by cyclic voltammetry in THF. Regardless of the scan rates, two reversible redox waves were observed for reduction processes at $E_{1 / 2}=-1.45 \mathrm{~V}$ and $-1.66 \mathrm{~V}$ (vs. $\mathrm{Fc} / \mathrm{Fc}^{+}$), in addition to redox waves for an oxidation process at $E_{1 / 2}=+0.62 \mathrm{~V}$. The multi-step reduction process was not observed in a previously synthesized singly boron-embedded polycyclic aromatic system within the measured potential window. ${ }^{14 c}$ Thus, the second boron atom in 1a is crucial for the storage of two electrons on the polycyclic aromatic framework. ${ }^{23}$

The two boron atoms also play an important role for the formation of a stable closed-shell structure of the boron-doped nanographene skeleton in 1. Based on previous theoretical calculations, parent nanographene 3 with zigzag edges was expected to exhibit a singlet biradical character, ${ }^{\mathbf{1 4 d}}$ similar to teranthene, which was recently reported by Kubo and coworkers. ${ }^{24}$ Notably, the two-electron reduced species $\mathbf{1}^{2-}$ is 


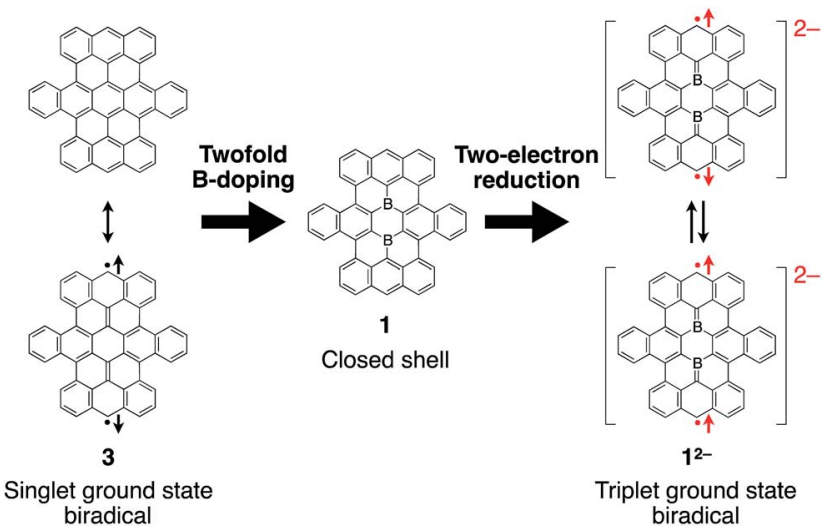

Fig. 5 Isoelectronic relationship between parent nanographene 3 and reduced boron-doped nanographene $1^{2-}$.

isoelectronic with parent nanographene 3 (Fig. 5). The biradical character of the dianionic species $\mathbf{1}^{2-}$ is therefore an interesting subject to study, which should depend on the coupling of the unpaired electrons across the boron-doped polycyclic framework.

The reduction processes were monitored in situ by visibleNIR absorption spectroscopy (Fig. 6). The first one-electron reduction occurred at $E_{\text {app }}=-1.1 \mathrm{~V}\left(v s . \mathrm{Ag} / \mathrm{Ag}^{+}\right)$and the absorption spectrum gradually changed accordingly, i.e. new absorption bands appeared at 790 and $950 \mathrm{~nm}$ with clear isosbestic points. The observed low-energy absorption bands reaching the wavelength of $1000 \mathrm{~nm}$ are consistent with an open-shell character of the radical anion. ${ }^{25}$ The second reduction occurred upon applying a voltage of $E_{\text {app }}=-1.6 \mathrm{~V}$, resulting in the appearance of broad absorption bands at 600 ,

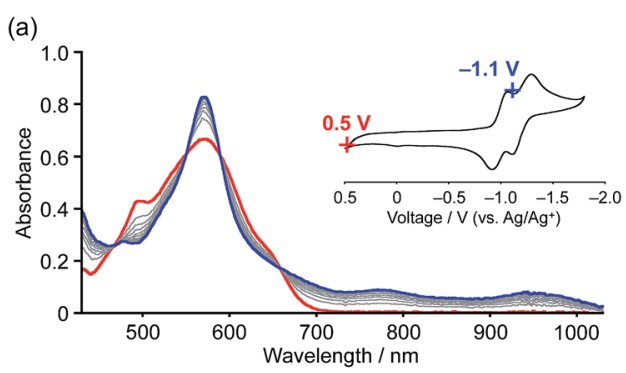

(b)

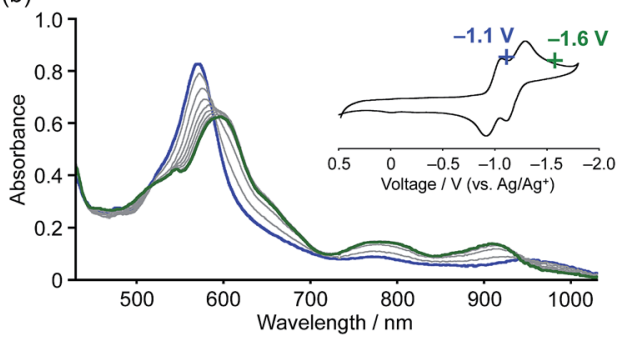

Fig. 6 In situ visible-NIR absorption spectra of 1a during electrochemical reduction in 0 -dichlorobenzene $\left(3.4 \times 10^{-4} \mathrm{M}\right)$. Working electrode: Pt mesh; reference electrode: $\mathrm{Ag} / \mathrm{AgNO}_{3}$; electrolyte: $0.1 \mathrm{M}$ $\left[(n \mathrm{Bu})_{4} \mathrm{~N}\right]\left[\mathrm{PF}_{6}\right]$.
790, and $920 \mathrm{~nm}$. The distinct two-step spectral change is indicative of the generation of dianionic species $1 \mathrm{a}^{2-}$. Reverting the applied voltage to $E_{\text {app }}=+0.5 \mathrm{~V}$ resulted in a recovery of the absorption spectrum of the neutral state (Fig. S14 $\dagger$ ).

We were also able to prepare dianion $\mathbf{1 a}^{2-}$ by chemical reduction, even though initial attempts to reduce $\mathbf{1 b}$ by treatment with an excess of $\mathrm{K}$ metal in THF failed due to unexpected over-reduction. X-ray crystallographic analysis revealed the generation of the corresponding trianionic monoradical of the parent polycyclic framework, in which all the peripheral alkoxy groups were removed via cleavage of the $\mathrm{C}\left(\mathrm{sp}^{2}\right)-\mathrm{O}$ bonds (Fig. S21 $\dagger$ ). ${ }^{26}$ Subsequently, we decided to use the milder reducing agent $\left[\mathrm{CoCp}_{2}{ }_{2}\right] \quad\left(\mathrm{Cp}^{*}=1,2,3,4,5\right.$-pentamethylcyclopentadienyl) for the preparation of the dianion. Upon addition of 2.5 equivalents to a solution of $1 \mathrm{a}$ in $o$-dichlorobenzene, the color of the solution changed from purple to green within $5 \mathrm{~min}$. The visible-NIR absorption spectrum of the solution, displaying broad absorption bands at 605, 790, and $900 \mathrm{~nm}$, is consistent with that of the electrochemically generated dianion $\mathbf{1 a}^{2-}$ (Fig. S15 and S16 $\dagger$ ). Therefore, we concluded that the dianion $2\left[\mathbf{C o C p}_{2}{ }_{2}\right]^{+} \cdot \mathbf{1 a}^{2-}$ was successfully generated.

The spin multiplicity of the dianion was investigated by variable-temperature ESR spectroscopy. ESR samples were prepared by treatment of $1 \mathrm{a}$ with 3.0 equivalents of $\left[\mathrm{CoCp}_{2}{ }_{2}\right]$ in $o$-dichlorobenzene. Both $\left[\mathrm{Co}(\mathrm{III})\left(\mathrm{Cp}^{*}\right)_{2}\right]^{+}$and unreacted $[\mathrm{Co}(\mathrm{II})$ $\mathrm{Cp}_{2}{ }_{2}$ ] are ESR-silent and should accordingly not interfere with the ESR studies. ${ }^{27}$ As the dianion $2\left[\mathbf{C o C p}_{2}{ }_{2}\right]^{+} \cdot \mathbf{1 a}^{2-}$ was found to be unstable in solution at room temperature, ESR measurements were carried out in frozen solution. The ESR spectra at $4 \mathrm{~K}$ exhibited a broad featureless signal in the $\Delta m_{\mathrm{S}}= \pm 1$ region centered at $g=2.0019$, indicating an open-shell biradical character for $2\left[\mathbf{C o C p}_{2}^{*}\right]^{+} \cdot \mathbf{1 a}^{2-}$ (Fig. 7a). Spin-spin interaction was confirmed by the observation of a weak forbidden signal in

(a)

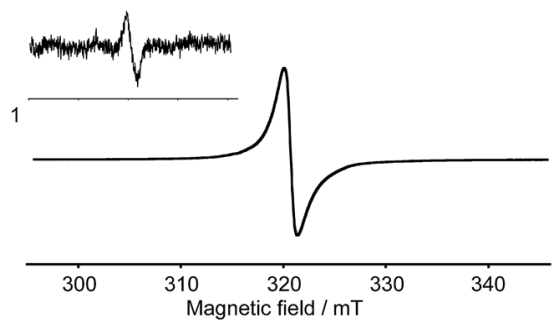

(b)

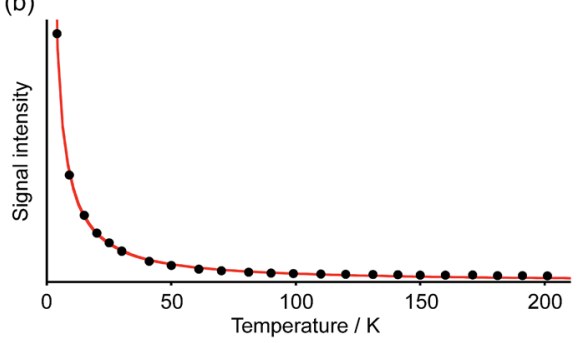

Fig. 7 (a) ESR spectrum of $2\left[\mathrm{CoCp}{ }_{2}\right]^{+} \cdot 1 a^{2-}$ in a frozen 0 -dichlorobenzene matrix at $4 \mathrm{~K}$. Inset: the weak forbidden $\Delta m_{\mathrm{S}}= \pm 2$ resonance at $4 \mathrm{~K}$; (b) temperature dependence of the ESR signal intensity of 2 $\left[\mathrm{CoCp}{ }_{2}\right]^{+} \cdot 1 \mathrm{a}^{2-}$ and curve-fitting with the Bleaney-Bowers equation. 
the half-field region $\left(\Delta m_{\mathrm{S}}= \pm 2\right)$. In order to determine the spin multiplicity of $2\left[\mathbf{C o C p}_{2}^{*}\right]^{+} \cdot \mathbf{1 a}^{2-}$ in the ground state, the temperature dependence of the resonance intensity for $\Delta m_{\mathrm{S}}=$ \pm 1 was examined in the $4-200 \mathrm{~K}$ range (Fig. $7 \mathrm{~b}$ ). The observed decreasing resonance intensity as a function of increasing temperature demonstrated that the dianion possesses a triplet ground state. Based on a curve fitting using the Bleaney-Bowers equation, an energy gap between the singlet and triplet states $\left(\Delta E_{\mathrm{ST}}\right)$ of $0.45 \mathrm{~kJ} \mathrm{~mol}^{-1}$ was estimated..$^{28}$ Accordingly, the triplet and singlet biradical states can be considered energetically close to each other. Upon warming the sample to room temperature, the ESR signal disappeared due to degradation of $1 \mathbf{a}^{2-}$.

The results of a theoretical study on the biradical character of model compound $\mathbf{1} \mathbf{b}^{\prime}$, in which the peripheral butoxy substituents of $\mathbf{1 b}$ were replaced with methoxy groups for simplicity, were in good agreement with the experimental results. DFT calculations (UB3LYP/6-311+G**) using the broken-symmetry method demonstrated that the energy level of the triplet state was slightly lower than that of the singlet biradical state, and the energy gap $\Delta E_{\mathrm{ST}}$ was calculated to be $0.38 \mathrm{~kJ}$ mol $^{-1}$ (Fig. S25†). ${ }^{29}$ As a result, despite being isoelectronic to neutral carbon analogue 3 , dianion $\mathbf{1}^{2-}$ has a different spin multiplicity in the ground state. In order to elucidate the origin of this difference, we reconsidered the molecular orbitals of neutral 1 (closed shell) and compared them with those of dicationic $3^{2+}$ (closed shell). ${ }^{14 d}$ Whereas the LUMO and LUMO+1 of $3^{2+}$ have almost identical spatial distributions but are different in energy $(\Delta E=0.31 \mathrm{eV})$, the corresponding orbitals of 1 show a remarkably different distribution with almost equivalent energy levels $(\Delta E=0.01 \mathrm{eV})$. These results suggest that the replacement of two carbon atoms with boron gives rise to a significant perturbation of the LUMO and LUMO+1 in the closed shell molecule prior to insertion of two electrons. The twofold reduction of $\mathbf{1}$ to $\mathbf{1}^{\mathbf{2}-}$ corresponds to a placement of two spins in the energetically similar LUMO and LUMO+1 according to Hund's rule. As a result, and in contrast to the singlet biradical ground state of $3, \mathbf{1}^{2-}$ adopts a triplet biradical ground state. The spatial distribution of the LUMO and LUMO+1 of 1 corresponds to those of the SOMOs in the triplet biradical state of $\mathbf{1}^{2-}$. One of the SOMOs is delocalized over the zig-zag edges, while the other is located over the central boron atoms and the

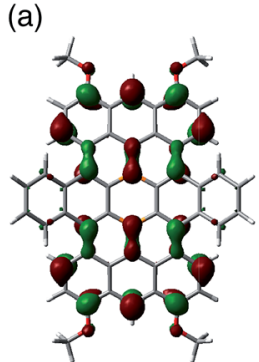

$193 a$

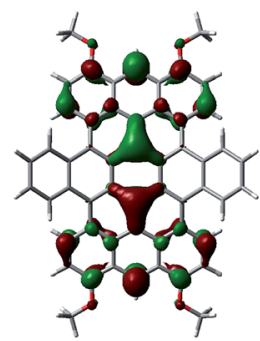

$194 a$ (b)

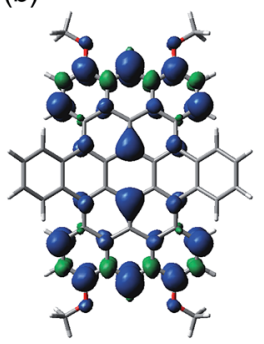

Fig. 8 (a) SOMOs and (b) calculated (UB3LYP/6-311+G**) spin density distribution of the model compound $1 b^{2-}$, in which the peripheral substituents of $1 \mathrm{~b}$ were replaced by methoxy groups for simplicity. zig-zag edges. The spin distribution map of the triplet state is consistent with a delocalization of the SOMOs (Fig. 8).

\section{Battery electrode performance}

Graphene has attracted considerable attention as a promising electrode material, mostly due to its outstanding electric and thermal conductivity and remarkable mechanical flexibility. Recently, Cheng and co-workers investigated boron-doped graphene as an anode material in Li-ion batteries and demonstrated its superior performance relative to pristine graphene. ${ }^{3}$ This report, regarding the positive effect of boron doping on battery performance, encouraged us to evaluate the properties of boron-doped nanographene $\mathbf{1}$ as an electrode material. A desirable advantage of relatively small molecules as electrode materials is the possibility to implement custom-tailored structural modifications at the molecular level. ${ }^{\mathbf{1 6 , 3 0}}$

The electrode performance of boron-doped nanographene 1 was evaluated using a half-cell with a Li metal counter electrode. The working electrode consisted of $10 \mathrm{wt} \%$ boron-doped nanographene 1a or $\mathbf{1 b}$ (active material), $70 \mathrm{wt} \%$ carbon black (conductive agent), and $20 \mathrm{wt} \%$ polyvinylidene difluoride (PVDF, binder). A $1.0 \mathrm{M}$ solution of $\mathrm{Li}\left[\mathrm{PF}_{6}\right]$ in diethyl carbonate/ ethylene carbonate was used as an electrolyte solution.

Charge/discharge tests were carried out at a constant current $(1 \mathrm{~mA})$ in the $1.5-4.0 \mathrm{~V}\left(v s . \mathrm{Li} / \mathrm{Li}^{+}\right)$voltage range. In light of the cyclic voltammogram of 1c (Fig. S17†), boron-doped nanographenes $\mathbf{1 a}$ and $\mathbf{1 b}$ were expected to exhibit a reversible twoelectron reduction process in this voltage range. The voltage profile of both batteries showed a gentle curve, and distinct plateau regions were not observed. For $\mathbf{1 a}$ and $\mathbf{1 b}$, first discharge capacity values of $111 \mathrm{~mA} \mathrm{~h} \mathrm{~g} \mathrm{~g}^{-1}$ and $160 \mathrm{~mA} \mathrm{~h} \mathrm{~g} \mathrm{~g}^{-1}$ were observed, respectively (Fig. S18 $\dagger$ ). As the peripheral alkoxy substituents are not expected to participate in the Li-ion storage because of the inert redox properties in this voltage range, ${ }^{31}$ compound $\mathbf{1 b}$, bearing more compact substituents relative to 1a, displayed a higher specific capacity.

In order to evaluate the cycle stability, the battery containing 1b was subjected to repeated charge/discharge cycles at a constant current density of $0.5 \mathrm{~mA} \mathrm{~cm}^{-2}$ in the $1.5-4.0 \mathrm{~V}$ ( $v \mathrm{~s}$. $\mathrm{Li}$ / $\mathrm{Li}^{+}$) voltage range. The obtained voltage profile did not show significant changes and a discharge capacity of $150 \mathrm{~mA} \mathrm{~h} \mathrm{~g}$ was retained even after 10 cycles, although the average discharging voltage is low when $\mathbf{1 b}$ would be used for cathode materials (Fig. 9a). In light of the degradation of the reduced boron-doped nanographene in solution, confirmed by the electrochemical study, the stable cycle performance should be attributed to its low solubility, which should suppress dissolution of the material into the electrolyte solution. ${ }^{30}$ Based on the theoretical capacity ( $29 \mathrm{~mA} \mathrm{~h} \mathrm{~g}^{-1}$ per electron) and considering the molecular weight of 1b, ca. 5-6 electrons/molecule were estimated to be involved in the charge/discharge process. Since a reference cell without active material showed only small capacity (13 $\mathrm{mA} \mathrm{h} \mathrm{g}{ }^{-1}$ ) in the same voltage range, electron storage by the carbon black and PVDF is limited (Fig. S19†). Thus, the total capacity of the boron-doped nanographene material is larger than the two-electron storage observed in the 
(a)

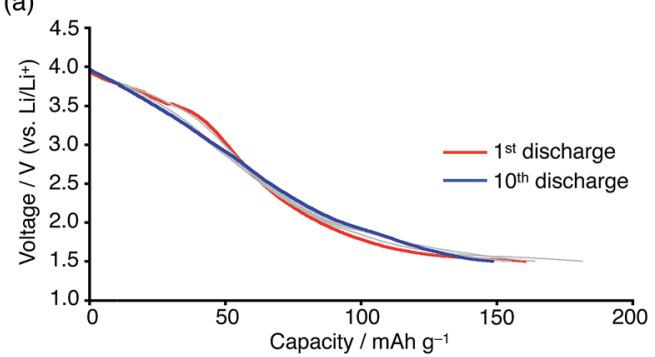

(b)



Fig. 9 (a) Discharge profile and (b) cycle performance of Li batteries containing boron-doped nanographene $1 \mathrm{~b}$ at a constant current density of $0.5 \mathrm{~mA} \mathrm{~cm}^{-2}$ in the $1.5-4.0 \mathrm{~V}$ voltage range (vs. $\mathrm{Li}^{\prime} / \mathrm{Li}^{+}$).

cyclic voltammetry, which should most likely be attributed to the super capacitor effect frequently observed in graphene materials. ${ }^{32}$

\section{Conclusions}

We have presented a comprehensive study on fundamental and characteristic properties and functions of boron-doped nanographenes containing two boron atoms. We have discussed their Lewis acidity, redox properties, and battery electrode performance. The boron atoms in the honeycomb framework act as Lewis acidic coordination sites and they form Lewis adducts with various Lewis bases. The change in coordination number of the boron atoms results in significant perturbations, not only with respect to the molecular structure, but also with regard to the electronic structure, which induced turn-on fluorescence response to gaseous $\mathrm{NH}_{3}$. The two-electron reduction of such twofold boron-doped nanographenes furnished a dianionic species, which exhibited a biradical character with a triplet ground state. This is in stark contrast to the singlet biradical character expected for the corresponding pristine carbonbased nanographene. Boron doping followed by the electron reduction may thus be considered an effective way to modulate the spin multiplicity of nanographenes. We have also examined the pivotal role of the peripheral substituents on the nanographene skeleton. Replacing the bulky mesityloxy groups with sterically less demanding alkoxy groups resulted in the formation of a more densely packed structure. When the boron-doped nanographenes were utilized as an active material for Li battery electrodes, the increased specific capacity was attained with the smaller substituents. A stable charge/discharge performance in the 1.5-4.0 V voltage range was displayed without any significant degradation even after 10 cycles. In conclusion, the precisely defined atomic structure of $\mathbf{1}$ enabled us to accurately elucidate the impact of boron doping on the characteristic properties and the functionality of nanographene materials at the molecular level. These findings should hence provide important fundamental guidelines for the design of advanced nanographene materials.

\section{Acknowledgements}

This work was partly supported by CREST, JST, and Grants-inAid for Scientific Research on Innovative Area (Stimuli-responsive Chemical Species, No. 24109007; Photosynergetics, No. 15H01083) and for Scientific Research A (No. 15H02163) from the Ministry of Education, Culture, Sports, Science, and Technology (MEXT) of Japan. K. M. thanks the JSPS for a Research Fellowship for Young Scientists. The authors are grateful to Dr Akihiro Shimizu (Kyoto Univ.) for fruitful discussions.

\section{Notes and references}

1 H. Liu, Y. Liu and D. Zhu, J. Mater. Chem., 2011, 21, 3335.

2 (a) Y.-B. Tang, L.-C. Yin, Y. Yang, X.-H. Bo, Y.-L. Cao, H.-E. Wang, W.-J. Zhang, I. Bello, S.-T. Lee, H.-M. Cheng and C.-S. Lee, ACS Nano, 2012, 6, 1970; (b) T. Wu, H. Shen, L. Sun, B. Cheng, B. Liu and J. Shen, New J. Chem., 2012, 36, 1385.

3 Z.-S. Wu, W. Ren, L. Xu, F. Li and H.-M. Cheng, ACS Nano, 2011, 5, 5463.

4 (a) J. Han, L. L. Zhang, S. Lee, J. Oh, K.-S. Lee, J. R. Potts, J. Ji, X. Zhao, R. S. Ruoff and S. Park, ACS Nano, 2013, 7, 19; (b) L. Niu, Z. Li, W. Hong, J. Sun, Z. Wang, L. Ma, J. Wang and S. Yang, Electrochim. Acta, 2013, 108, 666; (c) Z. Zuo, Z. Jiang and A. Manthiram, J. Mater. Chem. A, 2013, 1, 13476. 5 (a) T. Lin, F. Huang, J. Liang and Y. Wang, Energy Environ. Sci., 2011, 4, 862; (b) X. Li, L. Fan, Z. Li, K. Wang, M. Zhong, J. Wei, D. Wu and H. Zhu, Adv. Energy Mater., 2012, 2, 425; (c) H. Fang, C. Yu, T. Ma and J. Qiu, Chem. Commun., 2014, 50, 3328; (d) S.-M. Jung, I. T. Choi, K. Lim, J. Ko, J. C. Kim, J.-J. Lee, M. J. Ju, H. K. Kim and J.-B. Baek, Chem. Mater., 2014, 26, 3586.

6 (a) S. Kawai, S. Saito, S. Osumi, S. Yamaguchi, A. F. Foster, P. Spijker and E. Meyer, Nat. Commun., 2015, 6, 8098; (b) R. R. Cloke, T. Marangoni, G. D. Nguyen, T. Joshi, D. J. Rizzo, C. Bronner, T. Cao, S. G. Louie, M. F. Crommie and F. R. Fischer, J. Am. Chem. Soc., 2015, 137, 8872.

7 (a) H. Wang, Y. Zhou, D. Wu, L. Liao, S. Zhao, H. Peng and Z. Liu, Small, 2013, 9, 1316; (b) M. Cattelan, S. Agnoli, M. Favaro, D. Garoli, F. Romanato, M. Meneghetti, A. Barinov, P. Dudin and G. Granozzi, Chem. Mater., 2013, 25, 1490; (c) L. Zhao, M. Levendorf, S. Goncher, T. Schiros, L. Pálová, A. Zabet-Khosousi, K. T. Rim, C. Gutiérrez, D. Nordlund, C. Jaye, M. Hybertsen, D. Reichman, G. W. Flynn, J. Park and A. N. Pasupathy, Nano Lett., 2013, 13, 4659.

8 X. Lü, J. Wu, T. Lin, D. Wan, F. Huang, X. Xie and M. Jiang, J. Mater. Chem., 2011, 21, 10685. 
9 (a) Z.-H. Sheng, H.-L. Gao, W.-J. Bao, F.-B. Wang and X.-H. Xia, J. Mater. Chem., 2012, 22, 390; (b) S. M. Tan, H. L. Poh, Z. Sofer and M. Pumera, Analyst, 2013, 138, 4885; (c) L. Wang, Z. Sofer, P. Šimek, I. Tomandl and M. Pumera, J. Phys. Chem. C, 2013, 117, 23251; (d) X. Bo, M. Li, C. Han and L. Guo, Electrochim. Acta, 2013, 114, 582; (e) M. Xing, W. Fang, X. Yang, B. Tian and J. Zhang, Chem. Commun., 2014, 50, 6637; $(f)$ L. Zhang, Z.-Y. Zhang, R.-P. Liang, Y.-H. Li and J.-D. Qiu, Anal. Chem., 2014, 86, 4423; $(g)$ H. Li, B. Liu, Y. Wang, S. Yin, X. Ma, X. Wang, Q. Wu, R. Shen and H. Chen, RSC Adv., 2014, 4, 37992.

10 (a) A. Narita, X. Feng, Y. Hernandez, S. A. Jensen, M. Bonn, H. Yang, I. A. Verzhbitskiy, C. Casiraghi, M. R. Hansen, A. H. R. Koch, G. Fytas, O. Ivasenko, B. Li, K. S. Mali, T. Balandina, S. Mahesh, S. D. Feyter and K. Müllen, Nat. Chem., 2014, 6, 126; (b) L. Chen, Y. Hernandez, X. Feng and K. Müllen, Angew. Chem., Int. Ed., 2012, 51, 7640; (c) J. Cai, P. Ruffieux, R. Jaafar, M. Bieri, T. Braun, S. Blankenburg, M. Muoth, A. P. Seitsonen, M. Saleh, X. Feng, K. Müllen and R. Fasel, Nature, 2010, 466, 470; (d) L. Dössel, L. Gherghel, X. Feng and K. Müllen, Angew. Chem., Int. Ed., 2011, 50, 2540; (e) M. G. Schwab, A. Narita, Y. Hernandez, T. Balandina, K. S. Mali, S. D. Feyter, X. Feng and K. Müllen, J. Am. Chem. Soc., 2012, 134, 18169; (f) Y. Fogel, L. Zhi, A. Rouhanipour, D. Andrienko, H. J. Räder and K. Müllen, Macromolecules, 2009, 42, 6878; (g) X. Yang, X. Dou, A. Rouhanipour, L. Zhi, H. J. Räder and K. Müllen, J. Am. Chem. Soc., 2008, 130, 4216; (h) J. Wu, L. Gherghel, M. D. Watson, J. Li, Z. Wang, C. D. Simpson, U. Kolb and K. Müllen, Macromolecules, 2003, 36, 7082; (i) H. Omachi, T. Nakayama, E. Takahashi, Y. Segawa and K. Itami, Nat. Chem., 2013, 5, 572; (j) J. R. Sanchez-Valencia, T. Dienel, O. Gröning, I. Shorubalko, A. Mueller, M. Jansen, K. Amsharov, P. Ruffieux and R. Fasel, Nature, 2014, 512, 61.

11 (a) C. Bronner, S. Stremlau, M. Gille, F. Brauße, A. Haase, S. Hecht and P. Tegeder, Angew. Chem., Int. Ed., 2013, 52, 4422; (b) T. H. Vo, M. Shekhirev, D. A. Kunkel, F. Orange, M. J.-F. Guinel, A. Enders and A. Sinitskii, Chem. Commun., 2014, 50, 4172; (c) Y. Zhang, Y. Zhang, G. Li, J. Lu, X. Lin, S. Du, R. Berger, X. Feng, K. Müllen and H.-J. Gao, Appl. Phys. Lett., 2014, 105, 023101; (d) J. Cai, C. A. Pignedoli, L. Talirz, P. Ruffieux, H. Söde, L. Liang, V. Meunier, R. Berger, R. Li, X. Feng, K. Müllen and R. Fasel, Nat. Nanotechnol., 2014, 9, 896.

12 (a) S. M. Draper, D. J. Gregg and R. Madathil, J. Am. Chem. Soc., 2002, 124, 3486; (b) M. Takase, V. Enkelmann, D. Sebastiani, M. Baumgarten and K. Müllen, Angew. Chem., Int. Ed., 2007, 46, 5524; (c) M. Takase, T. Narita, W. Fujita, M. S. Asano, T. Nishinaga, H. Benten, K. Yoza and K. Müllen, J. Am. Chem. Soc., 2013, 135, 8031.

13 (a) X. Fang, H. Yang, J. W. Kampf, M. M. B. Holl and A. J. Ashe III, Organometallics, 2006, 25, 513; (b) C. A. Jaska, D. J. H. Emslie, M. J. D. Bosdet, W. E. Piers, T. S. Sorensen and M. Parvez, J. Am. Chem. Soc., 2006, 128, 10885; (c) M. J. D. Bosdet, W. E. Piers, T. S. Sorensen and M. Parvez, Angew. Chem., Int. Ed., 2007, 46, 4940; (d) T. Hatakeyama,
S. Hashimoto, S. Seki and M. Nakamura, J. Am. Chem. Soc., 2011, 133, 18614; (e) B. Neue, J. F. Araneda, W. E. Piers and M. Parvez, Angew. Chem., Int. Ed., 2013, 52, 9966; (f) X.-Y. Wang, F.-D. Zhuang, R.-B. Wang, X.-C. Wang, X.-Y. Cao, J.-Y. Wang and J. Pei, J. Am. Chem. Soc., 2014, 136, 3764 .

14 (a) Z. Zhou, A. Wakamiya, T. Kushida and S. Yamaguchi, J. Am. Chem. Soc., 2012, 134, 4529; (b) T. Kushida, C. Camacho, A. Shuto, S. Irle, M. Muramatsu, T. Katayama, S. Ito, Y. Nagasawa, H. Miyasaka, E. Sakuda, N. Kitamura, Z. Zhou, A. Wakamiya and S. Yamaguchi, Chem. Sci., 2014, 5, 1296; (c) S. Saito, K. Matsuo and S. Yamaguchi, J. Am. Chem. Soc., 2012, 134, 9130; (d) C. Dou, S. Saito, K. Matsuo, I. Hisaki and S. Yamaguchi, Angew. Chem., Int. Ed., 2012, 51, 12206; (e) K. Matsuo, S. Saito and S. Yamaguchi, J. Am. Chem. Soc., 2014, 136, 12580.

15 (a) V. Coropceanu, J. Cornil, D. A. S. Filho, Y. Olivier, R. Silbey and J.-L. Brédas, Chem. Rev., 2007, 107, 926; (b) K. Takimiya, S. Shinamura, I. Osaka and E. Miyazaki, Adv. Mater., 2011, 23, 4347.

16 Y. Morita, S. Nishida, T. Murata, M. Moriguchi, A. Ueda, M. Satoh, K. Arifuku, K. Sato and T. Takui, Nat. Mater., 2011, 10, 947.

17 N. K. S. Davis, M. Pawlicki and H. L. Anderson, Org. Lett., 2008, 10, 3945.

18 C. Dou, S. Saito and S. Yamaguchi, J. Am. Chem. Soc., 2013, 135, 9346.

19 (a) J. Dai, J. Yuan and P. Giannozzi, Appl. Phys. Lett., 2009, 95, 232105; (b) Y. G. Zhou, X. T. Zu, F. Gao, J. L. Nie and H. Y. Xiao, J. Appl. Phys., 2009, 105, 014309; (c) X. Kong and Q. Chen, J. Mater. Chem., 2012, 22, 15336; (d) C. L. Muhich, J. Y. Westcott IV, T. C. Morris, A. W. Weimer and C. B. Musgrave, J. Phys. Chem. C, 2013, 117, 10523; (e) S. Sharma and A. S. Verma, Phys. B, 2013, 427, 12; $(f)$ S. M. Seyed-Talebi, J. Beheshtian and M. Neek-amal, $J$. Appl. Phys., 2013, 114, 124307.

$20 \mathrm{H}$. Nöth and B. Wrackmeyer, NMR Basic Principles and Progress, Nuclear Magnetic Resonance Spectroscopy of Boron Compounds, Springer-Verlag, Berlin, New York, 1978, vol. 14. 21 S. L. S. Jacoby, J. S. Kowalik and J. T. Pizzo, Interative Methods for Nonlinear Optimization Problems, Prentice Hall, Inc., New Jersey, 1972.

22 H. Höpfl, J. Organomet. Chem., 1999, 581, 129.

23 (a) C. Reus, S. Weidlich, M. Bolte, H.-W. Lerner and M. Wagner, J. Am. Chem. Soc., 2013, 135, 12892; (b) A. Hübner, A. M. Diehl, M. Diefenbach, B. Endeward, M. Bolte, H.-W. Lerner, M. C. Holthausen and M. Wagner, Angew. Chem., Int. Ed., 2014, 53, 4832; (c) V. M. Hertz, M. Bolte, H.-W. Lerner and M. Wagner, Angew. Chem., Int. Ed., 2015, 54, 8800.

24 A. Konishi, Y. Hirao, M. Nakano, A. Shimizu, E. Botek, B. Champagne, D. Shiomi, K. Sato, T. Takui, K. Matsumoto, H. Kurata and T. Kubo, J. Am. Chem. Soc., 2010, 132, 11021.

25 (a) T. Shida and S. Iwata, J. Am. Chem. Soc., 1973, 95, 3473; (b) T. Shida, S. Iwata and M. Imamura, J. Phys. Chem., 1974, 78, 
741; (c) C. Hoffend, F. Schödel, M. Bolte, H.-W. Lerner and M. Wagner, Chem.-Eur. J., 2012, 18, 15394.

26 A. Maercker, Angew. Chem.,Int. Ed., 1987, 26, 972.

27 N. G. Connelly and W. E. Geiger, Chem. Rev., 1996, 96, 877.

28 B. Bleaney and K. D. Bowers, Proc. R. Soc. London, Ser. A, 1952, 214, 451.

29 (a) L. Noodleman, J. Chem. Phys., 1981, 74, 5737; (b) L. Noodleman and E. J. Baerends, J. Am. Chem. Soc., 1984, 106, 2316; (c) K. Yamaguchi, Y. Takahara, T. Fueno and K. Nasu, Jpn. J. Appl. Phys., 1987, 26, L1362; (d)
K. Yamaguchi, F. Jensen, A. Dorigo and K. N. Houk, Chem. Phys. Lett., 1988, 149, 537.

30 Y. Liang, Z. Tao and J. Chen, Adv. Energy. Mater., 2012, 2, 742. 31 T. Thornton, N. F. Woolsey and D. E. Bartak, J. Am. Chem. Soc., 1986, 108, 6497.

32 (a) H. Wang, Z. Zeng, N. Kawasaki, H. Eckert, H. Yoshikawa and K. Awaga, Chem.-Eur. J., 2013, 19, 11235; (b) N.-S. Choi, Z. Chen, S. A. Freunberger, X. Ji, Y.-K. Sun, K. Amine, G. Yushin, L. F. Nazar, J. Cho and P. G. Bruce, Angew. Chem., Int. Ed., 2012, 51, 9994; (c) L. L. Zhang, R. Zhou and X. S. Zhao, J. Mater. Chem., 2010, 20, 5983. 